\title{
FAKTOR-FAKTOR YANG MEMPENGARUHI KUALITAS HIDUP \\ PASIEN GAGAL GINJAL KRONIS YANG MENJALANI TERAPI \\ HAEMODIALISA DI RSU KABUPATEN TANGERANG \\ *Parta Suhanda
}

\begin{abstract}
ABSTRAK
Gagal Ginjal Kronik merupakan keadaan dimana ginjal tidak dapat lagi menjalankan fungsinya dengan baik, sehingga untuk menjaga Homeostasis tubuh, ginjal perlu menjalankan dyalisa, terapi ini dapat mempengaruhi kualitas hidup pasien. Tujuan penelitian ini mengetahui factor-faktor yang mempengaruhi kualitas hidup pasien gagal ginjal kronis. Metode penelitian menggunakan desain crosectional sampel adalah pasien gagal ginjal kronis yang sedang menjalani terapi haemodialisa di RSU Kabupaten Tangerang sebanyak 53 orang. Hasil penelian : factor yang mempengaruhi kualitas hidup adalah : lama menjalani HD $(\mathrm{P}=0,019)$ sedangkan pekerjaan, tingkat pendidikan, usia, dan jenis kelamin tidak mempengaruhi kuliatas hidup pasien GGK di RSU Kabupaten Tangerang. Kesimpulan Kualitas hidup pasien GGK dipengaruhi oleh lamanya menjalani haemodialisa.
\end{abstract}

Kata kunci : GGK, haemodialisa, kualitas hidup

*Poltekkes Kemenkes Banten

\section{Pendahuluan}

Gagal Ginjal Kronik penduduk pertahun (Bakri, 2005), merupakan keadaan dimana ginjal diperkirakan pada tahun 2025 akan tidak dapat lagi menjalankan mencapai dua kalinya (Go et al., fungsinya dengan baik, sehingga 2004; Stevens et al., 2006). untuk menjaga Homeostasis tubuh, Komplikasi yang seringkali ginjal perlu menjalankan dyalisa ditemukan pada penderita GGK (cuci darah) setiap jangka waktu adalah anemia, gagal jantung, (Alam tertentu atau dengan melakukan Syamsir \& Hadibroto Iwan, 2007), transplantasi ginjal (Pearce, 1995).

Tingkat insidensi gagal ginjal hipertensi pulmonal (Adelwhab et.al,2009), hiperkalemia dan aritmia kronik (GGK) di Indonesia akhir(Kartikasari, 2010).

akhir ini cenderung meningkat sebesar $200-250$ orang tiap 1 juta 
Terapi dialisa atau hemodialisa diperlukan perawatan yang intensif dan juga perlu biaya yang mahal, selain itu GGK biasanya memiliki kualitas hidup lebih rendah (Cohen et al., 2007; Scot et al., 2007; Wu et al., 2004)

Gagal ginjal terminal dapat membuat penurunan pada kualitas hidup, sehingga insidensi kematian karena gagal ginjal terminal ini juga semakin meningkat sesuai dengan peningkatan kejadiannya. Amerika serikat mencapai 71.000 pada tahun 2000 dan diperkirakan akan meningkat mencapai 352.000 pada tahun 2030 (Schoolwerth et al., 2006), untuk itu diperlukan upayaupaya pencegahan sehingga tidak sampai terjadinya gagal ginjal kronik.

Kualitas hidup penderita GGK yang menurun kemungkinan akan dipengaruhi oleh faktor usia, jenis kelamin, pendidikan, pekerjaan dan lama haemodialisa. Untuk membuktikan kondisi tersebut perlu dilakukan penelitiaan.

\section{Metodologi Penelitian}

Penelitian ini merupakan penelitian observasional analitik dengan rancangan cross sectional. Populasi pada penelitian ini adalah Semua klien gagal ginjal kronik yang menjalani terapi hemodialisis di RSU Tangerang. Dan Sampel berjumlah 53 orang dengan criteria inklusi ; Pasien GGK yang menjalani terapi HD di RSU Tangerang dengan kesadaran baik, serta bersedia mengikuti penelitian dan menandatangani surat persetujuan.

Pengumpulan data dengan menggunalan alat berupa kuisionerr untuk mengkaji kualitas hidup, digunakan intrumen Qualiti of life index Dialysis version III terdiri dari 31 pertanyaan, pengembangan oleh Ferrans dan Fower 1996, dan Yosi 2010.

Selanjutnya analisa univariat dilakukan untuk mendeskripsikan karakteristik dari masing-masing variabel yang di teliti, Analisa bivariat menggunakan uji Chi Square. Dan Uji Mulivariat (regresi logistic ganda). 
Hasil

Penelitian ini dilakukan selama bulan 2 bulan, di ruang Haemodialisa RSU Tangerang, dengan hasil sebagai berikut :

Tabel 1

Distibusi responden yang menjalani Haemodialisa menurut jenis Kelamin Di RSU Tangerang

\begin{tabular}{llcc}
\hline No & Jenis Kelamin & Jml & \% \\
\hline 1. & Laki-laki & 37 & 69.8 \\
2. & Perempuan & 16 & 30.2 \\
\hline & Jumlah & 53 & 100,0 \\
\hline
\end{tabular}

Dari table 4,1 responden yang menjalani haemodialisa sebagian besar $69.8 \%$, jenis kelamin laki-laki

Tabel 2

Distibusi Responden yang menjalani Haemodialisa menurut kelompok umur Di RSU Tangerang

\begin{tabular}{lccc}
\hline No & $\begin{array}{c}\text { Kelompok } \\
\text { Umur }\end{array}$ & Jumlah & \% \\
\hline 1. & $<55$ tahun & 32 & 60.4 \\
2. & $\geq 55$ tahun & 21 & 39.6 \\
\hline & Jumlah & 53 & 100,0
\end{tabular}

Dari table 2 responden yang menjalani haemodialisa di RSU Tangerang sebagian besar 60,4 \% tergolong kelompok usia $<50$ tahun.
Tabel 3

Distibusi responden yang menjalani Haemodialisa menurut Lama Menjalani HD Di RSU Tangerang,

\begin{tabular}{|c|c|c|c|}
\hline No & Lama HD & Jumlah & $\%$ \\
\hline 1. & $<5$ tahun & 8 & 15.1 \\
\hline \multirow[t]{2}{*}{2.} & $\geq 5$ tahun & 45 & 84.9 \\
\hline & Jumlah & 53 & 100,0 \\
\hline $\begin{array}{l}\text { Dari } \\
\text { menja } \\
\text { Tange } \\
\text { lebih }\end{array}$ & $\begin{array}{ll}\text { table } & 3 \\
\text { ani } & \text { haem } \\
\text { ang } & \text { sebag } \\
\text { ari } 5 & \text { tahun }\end{array}$ & $\begin{array}{l}\text { responde } \\
\text { dialisa } \\
\text { an besar }\end{array}$ & $\begin{array}{l}\text { yang } \\
\text { RSU } \\
9 \%\end{array}$ \\
\hline
\end{tabular}

Tabel 4

Distibusi responden yang menjalani Haemodialisa menurut Kualitas Hidup di RSU Tangerang

\begin{tabular}{llcc}
\hline No & $\begin{array}{c}\text { Kualitas } \\
\text { Hidup }\end{array}$ & Jumlah & \% \\
\hline 1. & $\begin{array}{l}\text { Kurang } \\
\text { Baik }\end{array}$ & 19 & 35.8 \\
2. & Baik & 34 & 64.2 \\
\hline & Jumlah & 53 & 100,0 \\
\hline
\end{tabular}

Dari table 4 responden yang menjalani haemodialisa di RSU Tangerang sebagian besar $64.2 \%$ kualitas hidup baik. 
Tabel 5

Distibusi responden Haemodialisa menurut Tingkat Pendidikan di RSU Tangerang

\begin{tabular}{|c|c|c|c|}
\hline No & Pendidikan & Jumlah & $\%$ \\
\hline 1. & Rendah & 14 & 26.4 \\
\hline 2. & Tinggi & 39 & 73.6 \\
\hline & Jumlah & 53 & 100,0 \\
\hline
\end{tabular}
menjalani haemodialisa di RSU Tangerang sebagian besar $73.6 \%$ berpendidikan tinggi.

Tabel 6

Distibusi responden Haemodialisa menurut Kualitas Hidup di RSU Tangerang

\begin{tabular}{llcc}
\hline No & Pekerjaan & Jumlah & \% \\
\hline 1. & Tidak bekerja & 30 & 56.6 \\
2. & Bekerja & 23 & 43.4 \\
& & & \\
\hline & Jumlah & 53 & 100,0
\end{tabular}

Dari table 6 responden yang menjalani haemodialisa di RSU Tangerang sebagian besar $56.6 \%$ tidak bekerja.

Tabel 7

Distribusi Pasien GGK menurut Lama Menjalani Haemodialisa dan Kualitas Hidup Di RSU Kabupaten Tangerang Tahun 2014

\begin{tabular}{|c|c|c|c|c|c|c|c|c|}
\hline \multirow{3}{*}{$\begin{array}{l}\text { Lama } \\
\text { HD }\end{array}$} & \multicolumn{6}{|c|}{ Kualitas Hidup } & \multirow{3}{*}{$\begin{array}{c}\text { Nilai } \\
\mathbf{P}\end{array}$} & \multirow{3}{*}{$\begin{array}{c}\text { OR } \\
95 \% \\
\text { CI }\end{array}$} \\
\hline & \multicolumn{2}{|c|}{ Kurang } & \multicolumn{2}{|c|}{ Baik } & \multicolumn{2}{|c|}{ Total } & & \\
\hline & $\mathrm{N}$ & $\%$ & $\mathrm{~N}$ & $\%$ & $\mathrm{n}$ & $\%$ & & \\
\hline$\geq 5$ th & 6 & 75 & 2 & 25 & 8 & 100 & 0,02 & 7,385 \\
\hline$<5$ th & 13 & 28.9 & 32 & 71.1 & 45 & 100 & & $\begin{array}{c}(1,315 \\
-\end{array}$ \\
\hline Jml & 19 & 35.8 & 34 & 64.2 & 53 & 100 & & $41,46)$ \\
\hline
\end{tabular}

Tabel 7 menunjukkan bahwa kualitas hidup kurang lebih banyak terjadi $(75,0 \%)$ pada pasien hemodialisa dengan lama $H D \geq 5$ tahun, jika dibandingkan dengan kelompok pasien hemodialisa yang lama HD nya $<5$ tahun, hanya $28,9 \%$ yang memiliki kualitas hidup kurangDari 53 orang responden yang lama HD < 5 tahun sebanyak 28,9\% mempunyai kualitas hidupnya kurang baik. Dari hasil uji statistik diperoleh nilai $\mathrm{P}$ 0,019 dan nilai OR 7.385 (95\% CI: 1,315 - 41,457). Dengan demikian secara statistik pada tingkat kepercayaan $95 \%$ terdapat hubungan yang bermakna antara lama menjalani HD dengan kualitas hidup dimana responden yang menjalani HD lebih dari 5 tahun berisiko 7 kali lebih besar untuk mempunyai kulitas hidup kurang baik dibanding dengan responden yang lama HD kurang dari 5 tahun. 
Tabel 8

Distribusi Pasien GGK

menurut Usia dan Kualitas

Hidup Di RSU Kabupaten

Tangerang

\begin{tabular}{|c|c|c|c|c|c|c|c|}
\hline \multirow{3}{*}{ Usia } & \multicolumn{6}{|c|}{ Kualitas Hidup } & \multirow{3}{*}{$\begin{array}{c}\text { Nilai } \\
\mathbf{P}\end{array}$} \\
\hline & \multicolumn{2}{|c|}{ Kurang } & \multicolumn{2}{|c|}{ Baik } & \multicolumn{2}{|c|}{ Total } & \\
\hline & $\mathrm{N}$ & $\%$ & $\mathrm{~N}$ & $\%$ & $\mathrm{~N}$ & $\%$ & \\
\hline$\geq 55$ tahun & 8 & 38.1 & 13 & 61.9 & 21 & 100 & 1.000 \\
\hline$<55$ tahun & 11 & 34.4 & 21 & 65.6 & 32 & 100 & \\
\hline Jumlah & 19 & 35.8 & 34 & 64.2 & 54 & 100 & \\
\hline \multicolumn{8}{|c|}{$\begin{array}{l}\text { Dari table } 8 \text { menunjukan tidak ada } \\
\text { hubungan yang bermakna }(\mathrm{P}>1.000) \\
\text { antara usia dan kualitas hidup. }\end{array}$} \\
\hline & \multicolumn{7}{|c|}{$\begin{array}{l}\text { Distribusi Pasien GGK } \\
\text { menurut Jenis Kelamin dan } \\
\text { Kualitas Hidup Di RSU } \\
\text { Kabupaten Tangerang }\end{array}$} \\
\hline \multirow{3}{*}{ Jen Kel } & \multicolumn{6}{|c|}{ Kualitas Hidup } & Nilai \\
\hline & \multicolumn{2}{|c|}{ Kurang } & \multicolumn{2}{|c|}{ Baik } & \multicolumn{2}{|c|}{ Total } & $\mathbf{P}$ \\
\hline & $\mathrm{N}$ & $\%$ & $\mathrm{~N}$ & $\%$ & $\mathrm{~N}$ & $\%$ & \\
\hline Perempuan & 4 & 25 & 12 & 75 & 16 & 100 & 0.358 \\
\hline Laki-laki & 15 & 40.5 & 22 & 59.5 & 37 & 100 & \\
\hline Jumlah & 19 & 35.8 & 34 & 64.2 & 53 & 100 & \\
\hline
\end{tabular}

Dari table 9 menunjukan tidak ada hubungan yang bermakna ( $\mathrm{P}>0.358)$ antara jenis kelamin dan kualitas hidup.

Tabel 10

Distribusi Pasien GGK menurut Pendidikan dan Kualitas Hidup Di RSU Kabupaten Tangerang

\begin{tabular}{lccccccc}
\hline \multirow{3}{*}{ Pndidikan } & \multicolumn{6}{c}{ Kualitas Hidup } & Nilai \\
\cline { 2 - 7 } & \multicolumn{2}{c}{ Kurang } & \multicolumn{2}{c}{ Baik } & \multicolumn{2}{c}{ Total } & P \\
\cline { 2 - 7 } Rendah & $\mathrm{N}$ & $\%$ & $\mathrm{~N}$ & $\%$ & $\mathrm{~N}$ & $\%$ & \\
Tinggi & 7 & 50 & 7 & 50 & 14 & 100 & $\mathbf{0 . 2 1 5}$ \\
\hline Jumlah & $\mathbf{1 9}$ & 30.8 & 27 & 69.2 & 39 & 100 & \\
\hline
\end{tabular}

Dari table 11 menunjukan tidak ada hubungan yang bermakna $(\mathrm{P}>0.215)$ antara pendidikan dan kualitas hidup.
Tabel 11

Distribusi Pasien GGK

menurut Pekerjaan dan Kualitas

Hidup Di RSU Kabupaten

Tangerang

\begin{tabular}{|c|c|c|c|c|c|c|c|}
\hline \multirow{3}{*}{ Pekerjaan } & \multicolumn{6}{|c|}{ Kualitas Hidup } & \multirow{2}{*}{$\begin{array}{c}\text { Nilai } \\
\mathbf{P}\end{array}$} \\
\hline & \multicolumn{2}{|c|}{ Kurang } & \multicolumn{2}{|c|}{ Baik } & \multicolumn{2}{|c|}{ Total } & \\
\hline & $\mathrm{N}$ & $\%$ & $\mathrm{~N}$ & $\%$ & $\mathrm{~N}$ & $\%$ & \\
\hline Tdk bkerja & 14 & 46.7 & 16 & 53.3 & 30 & 100 & 0.09 \\
\hline Bekerja & 5 & 21.7 & 18 & 78.3 & 23 & 100 & \\
\hline Jumlah & 19 & & 34 & & & 100 & \\
\hline
\end{tabular}

Dari table 11 menunjukan tidak ada hubungan yang bermakna $(\mathrm{P}>0.09)$ antara pekerjaan dan kualitas hidup.

\section{Pembahasan}

Pada pembahasan ini penulis menginterprestasikan hasil penelitian dengan permasalahan yang ada dan hasil-hasil penelitian orang lain yang terkait sebagai berikut:

Hasil penelitian ini menunjukan bahwa : Responden yang menjalani HD sebagian besar $69,8 \%$ adalah laki-laki, hal ini menunjukan bahwa kejadian gagal ginjal kronis lebih banyak terjadi pada kelompok lakilaki., kondisi ini sesuai dengan hasil penelitian yang menyebutkan lakilaki mempunyai kualitas hidup lebih jelek dibanding perempuan, semakin lama menjalani haemodialisa semakin rendah kualitas hidupnya (avis 2005, desita 2010,Yuliaw 2010). 
Pada kelompok umur/usia, sebagian besar $60.4 \%$ ada pada kelompok < 55 tahun. Dari beberapa sumber menyebutkan pasien diusia > 55 tahun akan bertambah komplikasi yang terjadi. Hal ini menunjukan bahwa semakin tua usia maka kualitas hidup semakin menurun Kondisi ini sesuai hasil penelitian Indonesia Nursing 2008 yang menyebutkan bahwa prognosis dan harapan hidup erat kaitannya dengan usia dimana usia diatas 55 tahun cenderung timbul berbagai komplikasi yang memperberat fungsi ginjal dibanding usia dibawah 40 tahun.

Pada kelompok pendidikan, sebagian besar $73.6 \%$ tergolong pendidikan tinggi (SMA/PT), kondisi ini merupakan factor yang akan mendukung keberhasilan program terapi, sehingga akan meningkatkan kualitas hidup pasien tersebut. Pasien dapat mengontrol dirinya dalam menghadapi masalah yang dihadapi, rasa percaya diri yang tinggi, pegalaman dan pikiran yang tepat dalam menghadapi permsalahan (sapri, 2008)
Pada kelompok pekerjaan, sebagian besar (56.6\%) ada pada kelompok tidak bekerja/pensiunan, hal ini ada kaitannya dengan factor usia, dimana mereka sudah tidak terkait lagi dengan pekerjaan karena sudah purna tugas.

Pada kelompok lamanya menjalani HD, sebagian besar $84.9 \%$ lebih dari 5 tahun.. Kondisi ini menunjukan bahwa pasien sudah lama menjalani $\mathrm{HD}$, sehingga pasien sudah dapat beradaptasi dengan baik dan sudah banyak informasi yang diterima dari petugas kesehatan (sapri,2008).

Kualitas hidup pasien yang menjalani haemodialisa di RSU Tangerang September 2013, sebagian besar $64,2 \%$ ada pada katagori baik. Kondisi ini menunjukan bahwa sebagian besar responden kualitas hidupnya baik. Penilaian baik ini diambil dari 4 dimensi yaitu dimensi fisik, psikologi, social, dan lingkungan.

Hasil Analisa Bivariat sebagai berikut : Hasil penelitian terkait apakah ada hubungan antara usia, jenis kelamin, pendidikan dan 
pekerjaan hasil menunjukan tidak ada hubungan ( $\mathrm{P}>0.05)$. Hasil ini tidak sejalan dengan hasil penelitian wahyu ningsih (2011),dan Peneliti lain juga menjelaskan bahwa faktorfaktor yang mempengaruhi kualitas hidup pasien GGK menurut Avis (2005, dalam Desita, 2010), Yuliaw (2010), Yuwono (2000) adalah factor usia, jenis kelamin, pendidikan dan pekerjaan. Pada penelitian ini dimungkinkan pelayanan petugas sudah sangat baik dan pasien sudah beradaptasi dengan kondisi penyakitnya.

Pasien dengan kualitas hidup baik diharapkan dapat mengurangi timbulnya komplikasi. Kondisi ini didukung oleh beberapa factor dimana pendidikan tergolong pendidikan tinggi. Menurut Yuwono 2000, bahwa kualitas hidup pasien GGK dipengaruhi oleh pendidikan, umur, jenis kelamin, etiologi GGK, cara terapi pengganti, status nutrisi, serta kondisi komorbid (Yuliaw,2010). Penelitian Yosi 2011, menyebutkan status komorbid merupakan factor dominan mempengaruhi kualitas hidup pasien
GGK. Ada satu factor yang berhubungan dengan kualitas hidup pada penelitian ini yaitu lama menjalani haemodialisa. Pasien yang menjalani HD lebih dari 5 tahu mempunyai resiko 7 kali memiliki kualitas hidup kurang dibanding yang menjalani kurang dari 5 tahun. Hasil ini perlu diantisipasi bagi pasien-pasien yang lebih lama (> 5tahun), untul lebih mendapat perhatian dari keluarga, maupun petugas kesehatan.

\section{Simpulan}

Berdasarkan hasil penelitian ini dapat dibuat kesimpulan sebagai berikut : terdapat hubungan yang bermakna antara lama HD dengan kualitas hidup pasien GGK yang menjalani Haemodialisa di RSU Kabupaten Tangerang, dimana pasien yang menjalani HD lebih dari 5 tahun memiliki resiko 7 kali mempunyai kualitas hidup kurang baik, dibanding yang kurang dari 5 tahun.

Pada penelitian ini hanya ada satu factor yang mempengaruhi 
kualitas hidup pasien GGK yang menjalani haemodialisa yaitu lama menjalani haemodialisa. Usia, Jenis kelamin, pekerjaan, dan pendidikan tidak ada hubungan yang bermakna (P> 0.05) dengan kualitas hidup pasien.

Oleh karena itu, untuk meningkatkan kualitas hidup pasien GGK diperlukan adanya upayaupaya dari petugas kesehatan seperti penyuluhan tentang diet, pencegahan komplikasi dan lain-lain

Perlu dilakukan penelitian lebih lanjut terkait kualitas hidup ini, untuk mencegah komplikasi

\section{Daftar Pustaka}

Alam Syamsir \& Hadibroto Iwan, 2007, Gagal Ginjal, Gramedia, Jakarta

Baron, R.A \& Byrne, D.1994. Social Psychology : Understanding Human Interaction $7^{\text {th }}$ ed.). Boston : Allyn and Bacon

Black \& Hawks. Medical Surgical Nursing Clinical Management for positive outcomes. 7 th edition. St Louis Missourr. Elsevier saunders

Brunner \& Suddarth, 2002, Buku

Ajar Keperawatan Medikal

Bedah, Jakarta, EGC

Chao, J., Zyzanski, S., \& Flocke, S. (1998). Choosing a family level indicator of family function. Families, Systems and Health, 16, 367-373.

Cohen, SD., Patel, SS., Khetpal, P. Peterson, RA., Kimmel, PL., 2007. Pain, sleep disturbance, and quality of life in patients with chronic kidney disease, Clin J Am Soc nephrol 2: 919925

Ferrans, C E \& Fowers.Description of the Quality of the Life Indek (QLI), 30 April 2013.

Go, A.S., Chertow, G.M., Fan, D., Hsu, C.Y., 2004. Chronic kidney disease and the risk of death, cardiovascular events and hospitalization, NEJM, 351:1296-305

Kartikasari Indha Dwi, 2010, Hubungan antara Hiperkalemia pada Pasien Gagal Ginjal Kronik dengan Timbulnya Aritmia di RSUD Kabupaten Jombang, Tesis, Jombang.

Kuo, H.W., Tsai, S.S., Tiao, M.M., Yang, C.Y., 2007. Epidemiological features of 
CKD in Taiwan, Am J Kidney Dis, 49:46-55

Lemeshow, S., Hosmer, Jr. D.W., Klar, J., Iwanga, S.K., 1997. Besar sampel dalam penelitian kesehatan.

Terjemahan.Cetakan pertama. Jogjakarta:Gadjah Mada University Press

Levey, A.S., Coresh, J., Balk, E., Kaustz, A.T., Levin, A., 2003. National Kidney Foundation practice guidelines for chronic kidney disease: evaluasi, klasifikasi and stratification; Ann Intern Med; 139:137 147

Yosi, S, 2010. Hubungan Penambahan Berat Badan antara dua waktu dialisa dengan kualitas hidup pasien
Haemodialisa di RSU Dr.M. Djamil Padang, Tesis 